\title{
Tracking Affective Labour for Agility \\ in the Quantified Workplace
}

Phoebe V. Moore

Accepted, pre-print version.

\section{Abstract}

Sensory and tracking technologies are being introduced into workplaces in ways Taylor and the Gilbreths could only have imagined. New work design experiments merge wellness with productivity to measure and modulate the affective and emotional labour of resilience that is necessary to survive the turbulence of the widespread incorporation of agile management systems, in which workers are expected to take symbolic direction from machines. The Quantified Workplace project was carried out by one company that fitted sensory algorithmic devices to workers' computers and bodies which, this article argues, identify workers' so-called agility and reveal management practices that track affective and emotional labour, categorized in the project as stress, subjective productivity and wellbeing, which identify workers' so-called agility. Capital's accelerated attempts to capture more areas of work capacities facilitate the conversion of labour power into a source of value but also results in alienation and abstraction. Participants' resistance to participation in the Quantified Workplace reveals tensions in the labour process when affect is measured in processes of corporate change.

Keywords: quantified work, body-studies quantified self, self-tracking, affective labour, emotional labour, agile, change management 


\section{Tracking Affective Labour for Agility \\ in the Quantified Workplace}

Phoebe V. Moore ${ }^{\mathrm{i}}$

'What makes you tick?'

Claude Shannon (1961)ii

\section{Introduction}

In the early $20^{\text {th }}$ century, when Taylor sought to identify the precision of the work of a 'first class man' and the Gilbreths looked for the 'one best way' to lay bricks, trade unions became very suspicious. Unions perceived scientific management as a method of speedup and as giving too much authority to machines (Nadworny, 1955). Now, work design methods accept the supremacy of machines in their apparent capacity to measure work; normalise the risks of continuous workplace transformations in 'agile' management systems; and use increasingly invasive tracking and surveillance technologies to decipher measurement of more types of labour, including affective labour, not to pay for it, but to identify to what extent workers can cope with accelerations of change in digitalised workplaces.

The article first outlines an emerging research area I have called Quantified Work, claiming that what this literature has not yet done in full is to look at specific management practices which work to quantify affective and emotional labour. To contribute to this emerging literature, which sits within 'quantified self' and body-studies debates, and to address the gaps outlined in the first section, the argument focusses on worker self- 
management and self-discipline for agility, as explicit forms of management and work design practice enhanced by quantifying and machinic technologies of measure.

The trend in workplace quantification for agility is theorised from a post-Marxist perspective, building on recent feminist work of Dewart-McEwen (2017) and Jarrett (2016), who look at that ways in which labour outside the formal employment relationship is exploited in digitalised environments, and are committed to feminist arguments where work is argued to be invisibilised through technologies (Crain et al, 2016; Cherry, 2016). While the history of work design also invisibilises affective and emotional labour, a new work design model has become increasingly popular since its inception in 2001, the agile (selfImanagement system, which serves to expose previously unseen aspects of work. Agile inverts the relationship between the machine and the body, where, because technology changes, workers are told to expect constant workplace transformation and to thus, constantly self-manage the effects of incessant change and to become subjectively 'agile'. The second section makes suggestions for theorising how agile self-management requires intensified affective labour, which is tied to self-tracking experiences of such changes and data creation for, potentially, intensified management processes through which the impact of workplace change can be assessed.

The final section then presents a case study highlighting worker responses and resistance to participation in a corporate-led worker tracking experiment locally called the Quantified Workplace held in Rotterdam, Netherlands, where tracking technologies were implemented to manage corporate change. The case study demonstrates the potential for intensified subsumption of human labour to capitalism, via accelerated attempts to quantify affective labour under conditions of continual transformations of digitalised workplaces and 
of raising expectations of productivity and wellness. The case study provides a precise example of digitalised management methods (Moore and Joyce, 2018) where systems and devices were introduced to track and measure affective and emotional labour for agility. These forms of personalised change management methods quickly revealed the tensions with these methods, as workers became increasingly aware both of personal experiences of affective and emotional labour, but also became sensitised to the possible impacts and implications of these activities. Of particular interest is the high level of disengagement and resistance to the experiment, demonstrating the issues of alienation and control surrounding such corporate initiatives in change management, as well as performance management, when bound up with new workplace surveillance technologies.

\section{Quantified work}

Here, I outline the literatures to which this paper contributes and the surrounding social context. While interest in self-tracking and self-archiving has a longer history (see Moore 2018a), the term 'quantified self' was popularised from 2008 (Lupton, 2013b: 26) and refers to the interest in optimisation through intensified personalised tracking practices with the use of technologies first introduced in medical and fitness circles. The term the quantified self became increasingly widespread throughout the media because of a range of Quantified Self events starting in Silicon Valley, driven by WIRED founding editor Kevin Kelly and journalist Gary Wolf in 2012-13. From that point, a quantified self literature emerged, advanced by Deborah Lupton (2012, 2013a, 2013b, 2013c, 2014, 2015, 2016a, 2016b) and including the work of Crawford et al (2015), Nafus (2016), Pantzar and Ruckenstein (2015), Ruckenstein (2014), and Schüll (2016). This literature addresses important questions of identity; self-governance, knowledge, optimisation, control, regulation and reflection; and 
implications for social interaction, as big data is gleaned from bodies in ways only hinted at when items such as the weight scale (Crawford et al, 2015), stethoscope, stopwatch and Taylor's own michronometer were first invented.

The quantified self literature contributes to body-studies and research on affect in that it looks closely at how bodies are measured using increasingly intimate practices with ever more precise measuring technologies, often in the pursuit of an idealised selfknowledge or what I have called the 'autonomic self' in my recent book: a 'self 'that would otherwise not be knowable' except through the help of new technologies that aid in biometric and physiological analyses (Moore, 2018a). Body-studies debates have been driven forward in the present journal Body \& Society since its inception in 1995 and are outlined in Blackmann's special issue on Affect (2010: 1), where a cross-disciplinary set of concepts emerging from feminism, sociology, anthropology, cultural history and philosophy are calibrated, to identify more recent themes of objects and practices in studies of technologies and labour. As stated, Lupton has led the debates on the quantified self and thus, body-studies, most recently warning about the function creep of dataveillance as it pervades ever-increasing spheres of life, including the body and social experiences. Lupton throws light on cases of self-tracking 'where the choice to participate may be limited' (2016b: 3). Here, I intend to build upon Lupton's argument, arguing that outside selfimprovement pursuits, self- and other-tracking is being incorporated into workplaces in ever more all-consuming ways, where the nature of the employment relationship and management practices are transforming rapidly.

To address the latest trends in quantification and body measurement studies, I identify a substratum of these debates in quantified self and body-studies, which I call 
quantified work. This mostly critical literature focusses on the rise in the use of metrics in subordinating the (supposed) body to the (supposed) mind, where calculation is inherently cognitive (Moore and Robinson 2016); surplus value is captured (Till, 2014); privacy is at stake (Ajana, 2017; Moore and Piwek, 2017); the risks of psychosocial and physical violence are on the rise (Akhtar and Moore, 2017; Moore, 2018b); working time is not paid (Hayes and Moore, 2016); power is deployed through metrics (Beer, 2016); control is enacted within the labour process via tracking technologies (Thompson and Briken, 2017; Moore and Joyce, 2018); reputations are constantly at stake (Gandini, 2016); and where worker quantification facilitates the social reproduction of capitalism (Jarrett, 2016), invisibilises labour in digital environments (Silberman and Irani, 2016) and intentionally masks 'unseen' labour (Moore, 2018a; also see Fuchs 2014). Self-tracking for health and wellbeing can be placed in the context of emerging trends in self-optimisation and the political economy of anxiety, couched in the rollback of the welfare state and rise in austerity, where, within neoliberal social relations, nothing is too precious for commodification and control. Management practices to suit such an environment are sometimes called 'gamification' if they are designed to become a pleasurable aspect of work and are part of a wellness 'syndrome' (Cederström and Spicer, 2015) backed by corporate productivity and benefit packages.

Quantified work research would further benefit from exploring the ways in which measurement and quantification are theorised such as seen in the research of Engster on the technique of measurement in Hegel and Marx (2017) and the entanglement of measurement, quantification and time (Engster, 2014); Elden's work on Heidegger and the politics of time and space (2005); Porter (1996) on the perceived objectivity in numbers; and 
on the ways algorithms are increasingly used for decision-making or are substituted for adequate human intervention (O'Neil, 2016; Pasquale, 2015). So, to begin this debate and to contribute to this trajectory of thinking, in particular contributing to feminist body-studies and the emerging quantified work literature, the present article highlights new entanglements in labour processes where techniques for quantifying affect and emotional labour begin to penetrate subjectivities and bodies.

\section{Responding effectively: affective labour for agility}

In 2001, 17 software developers, disillusioned with bureaucracy and obstacles to technological development, wrote the Agility Manifesto (The Agile Movement, 2008):

We are uncovering better ways of developing software by doing it and helping others do it. Through this work we have come to value: Individuals and interactions over processes and tools Working software over comprehensive documentation Customer collaboration over contract negotiation Responding to change over following a plan [italics added by present author] That is, while there is value in the items on the right, we value the items on the left more.

This manifesto reflected other IT workers' sentiment who felt the standard waterfall system used in factories was ineffectual for software development (Agile Movement, 2008). Agile approaches 'help teams respond to unpredictability through incremental, iterative work 
cadences and empirical feedback. Agilists propose alternatives to waterfall, or traditional sequential development' (The Agile Movement, 2008).

After its birth in 2001, companies in many industries began to adopt an agile system where workers and management should both have the 'ability over time to respond quickly and effectively to rapid change and high uncertainty' (Joroff et al, 2003: 294). Agile is a 'coevolution of workplace and work'; an adaptation of kaizen, or 'continuous improvement' (Danford et al, 2008); 'neither top-down nor bottom-up: it is outside-in' (Denning, 2015), relying on the conscious co-evolution and improvement of work which happens through 'experimentation, integration and disseminated learning' (Joroff et al, 2003: 294). 'Agile' has been appropriated into mainstream management terminology and job descriptions, even though it is unpopular with workers precisely because it breeds uncertainty, which the Chartered Institute for Personnel (CIPD) indicates in Getting Smart About Agile Working (2014).

While this set of management practices is heralded as a highly normative, horizontal system, its initiators made several assumptions and overlooked specific features of its operations that have and will have ongoing implications for workers. The Agility Manifesto inverts the hierarchy between humans and machines, where humans must be continuously transformative, because technology is apparently continuously transforming. In the agile method, humans are expected not only to become subject to rapid technological change and to self-manage these processes through affective labour but to in fact, emulate machines, which are expected to continuously develop and change; and to embrace constant subjective transformations. Meanwhile, workers are subject to increasingly 
intimate tracking and monitoring and their every move surveilled. Agile workers are prepared for constant change, happy to make personal changes, always on the move, always trackable.

The opening scroll for the film Bladerunner introduces the Nexus 6 replicants as being 'superior in strength and agility [to humans], and at least equal in intelligence'. Robots are perceived to be agile and we are competing directly with them at this stage in labour history. Agility pushes calculation practices into the affective realm through the quantification and measure of people's abilities to withstand incessant transformation of work/life as dictated by machinic transformation. Personal investment in self-managing agility requires constant social reproduction of a company's image through workers aligning themselves with the identities and preferences proffered by the company (Land and Taylor, 2010). Workers cannot log out or switch off (Gregg, 2011) and 'struggle to be left alone rather than to be included, a type of refusal that would have looked strange to their Fordist predecessors' (Fleming, 2015: 83). Humans have long used machines as tools, but now, devices identify our activities and aid management judgements at ever more intimate levels, as though we are the tools, playing a role in almost accidentally restructuring the parameters in which we work, behind the smoke and mirrors of inevitability. Lefebvre warns that 'the worker, instead of manipulating a tool, now serves a machine' (1991: 344).

Affective and emotional labour are part of the social reproductive labour that facilities the processes of agile, where unseen work serves to allow the continuation of capitalist labour relations and the reproduction of capitalist subjectivities (Dalla Costa and James, 1972; Fortunati and Fleming, 1995; Jarrett, 2015; Kofman, 2012; Haider and 
Mohandesi, 2015; Kofman and Raghuram, 2015; Dowling, 2016; Weeks, 2011; Hoskyns and Rai, 2007); forms of labour that become a 'moral' obligation imposed by corporate power; where subjectivities are required to be resilient to instability and where subjects take responsibility for personal wellness rather than associate stress and illness with poor working conditions. This puts worker resilience into the realm of a 'necessary part of social and ecological assemblages, which passes through the unconscious field' (Firth, 2016: 131).

Affective labour refers to 'forms of labour that produce and circulate states of being, feelings of well-being, desire, ease and passion' (Read, 2003: 128), which occur at a previsceral stage of experience. While affective labour is usually expected of women, it:

...does not refer to gender specific forms of work although at times defined as 'women's work'. AL refers to the interactive character of work, to its capacity to promote flows of communication, thus it is polyvalent with regard to the activities associated with it. (Federici 2011, 63)

Affective labour reaches below, behind and above the corporeal. Measuring it is a form of management control by means of the 'modulation of affect' (Bogard, 2010) by recording bodily capabilities, as in the study outlined below, by providing self-tracking devices, and thus potentially controlling resistance.

Not identical to affective labour, Hochschild (2012/1983) first labelled 'emotional labour' in 1983, illustrating self-management of emotion at work, whether it is through suppressing anger or frustration with customers or co-workers, or by providing 
entertainment and producing joy. Hochschild outlined such labour required of cabin crew and in debt collection work. Brook lists the work of 'nurses, Disneyland workers, retail and childcare workers, schoolteachers, psychotherapists, holiday representatives, call-centre workers, bar staff, waiters and many others' (2009: 8) as requiring emotional labour. Firth states that emotion 'usually refers to an individuated physical feeling (not mental or intellectual) that is passive (not active) and has a more-or-less irrational relationship to the world and outer life'. Altomonte (2015) notes that Hochschild focusses on corporate control over emotional and affective labour through explicit commodification.

Pinning to the corporeal, agile labourers do not engage in creative production using their own affective and emotional capacities. They are engaged in a type of repression by which the required subordinate performances corrode their own psychosomatic and bodily wellbeing where people are compelled to self-manage the impacts of seemingly inevitable workplace change, through affective labour. Management attempts to externally regulate and modulate all areas of labour and to externalise any costs that are part of this process. In the case of the Quantified Workplace project outlined below, workers became conscious of their own affective and emotional labour, which are classified here as falling within the areas of stress, subjective productivity and wellbeing, again, in the context of a corporate merger and a move toward agile systems. While affect is, by definition, innumerable, and outputs are potentially only seen as 'disembodied exhaust' (Smith, 2016) or contrived data proxies, it has historically been invisibilised and all socially reproductive labour excluded from payment systems. However, the pursuit of including affective labour into management systems now is not being carried out in order to pay for it, but because worker disengagement, resistance or collapse could reduce the company's 'bottom line'. 
Emphasising empowerment, Hardt and Negri (2000) illustrate affect and immaterial labour from a post-Fordist perspective as providing possibilities for resistance, collective subjectivities and formations of communities. Debates have been dominated by these authors' English language publications despite a myriad of other publications in German, French, Portuguese, Italian and Spanish-speaking spheres (Atzert et al, 2002; Atzert and Müller, 2004; Birkner and Foltin, 2006; Lazzarato et al, 1998; Piper et al, 2007; Corsani et al, 1996; Brumaria, Issue 7 2006; Blondeau et al, 2004; Borio et al, 2002; Lazzarato, 1997, cited in Dowling, Nunes and Trott, 2007: 1, 2). The emphasis on affect in management strategies can be seen, on the other hand, to be tied up with labour control and social reproduction of capitalist subjectivity and relations of masked coercion (Hartmann, 1976; Jarrett, 2016; Hochschild, 2012/1983). While affect enables or disables our power to act through the body and its power lies in its singularity and universality (Negri, 1999: 85), ,ii attempted corporate colonisation of affective labour has become endemic in post-Fordist management and postbureaucratic techniques precisely because worker solidarity that becomes possible via affect which humans can have upon one another, inspiring empathy and collectivity, would lead to the most difficult form of resistance to stop, since affect already infiltrates all-of-life.

While affective labour can involve a project that is productive of communities or 'constituting a form of life' (Hardt, 1999: 99), affective labour also involves negotiation of the penetration of capitalist management, now enhanced with a range of technologies outlined in the case study below. In this sense, affect, which is a feature of reproductive labour as Weeks argues, is not separable from capitalism $(2007 ; 2011)$ but involves preparatory and even defensive labour. So, in this sense, management systems have begun 
to seek to capture and control affective labour in part so that management can predict worker collapse under the paradoxical weight of agility, but also because when workers become conscious of affect, or their power to act, they also become conscious of their ability to impact one another and to potentially to collectively challenge abuses at work (Moore, 2018a). Rather than providing a buffer from the strains of work, new initiatives place unprecedented pressures on workers to cope with popular agile systems which accept the inevitability of constant transformation, a key tenet in Western modernity (Featherstone, 2010: 200) that is now being accelerated.

The process whereby affective and emotional labour are quantified involves attempts to capture 'invisible labour' which in feminist literature refers to work that goes unrecognised and overlooked (Crain et al, 2016). Through agile systems, then, capital attempts to turn the use-value in affective labour into an exchange, turning the concrete into divisibilities and abstractions, thus commodifying affect and circumventing resistance. Affective labour however, is not invisibilised without intention. Invisibility has the potential for revelation, but regulations for its viewing are already authored within specific parameters, dictating what is permissible, what is 'seen' and thus what is measured, which is a basic premise for the theory of working time (Hayes and Moore, 2016).

However, what is not counted in workplaces is as important as, if not more important than, what is counted (Cherry, 2016). Processes to monitor and track work using more intimate tracking methods as is seen in the Quantified Workplace project may bring working time to the fore, may render it 'seen', but will not necessarily result in remuneration. Heidegger's point that 'calculation refuses to let anything appear except 
what is countable' (1998: 235) is relevant here, where numeration associated with work may be revealed, but only for limited purpose. Instead, the hitherto externally invisible aspects of labour are revealed, but increasingly under the microscope of responsibilisation and potentially in the context of 'digital nihilism' (Gregg, 2015) where constant productivity tracking according to the mantra of 'Getting Things Done', hyper-individualises workers. Indeed, Gregg (2010) outlines active blockages to affective communication through pseudo office intimacy created by such activities as Secret Santas. In cases of 'gig work', both online and offline (Moore and Joyce, 2018), individual workers become accountable for reputations that are recounted by algorithm (Gandini et al, 2016); leaving little room for qualitative depiction of visibilised selfhood or non-competitive communities.

Some have equated self-tracking with forms of Taylorisation (Morozov, 2013), where Taylorism is a 'rationalization of body-machine-management relations' (Von Osten 2011: 135). In the 1980s the increasing use of computer technologies in various industries and services was 'not merely to displace traditional skills' but 'also to monitor and hence discipline the remaining workforce' (Hyman, 1987: 37). The selection of, and now, imminent resignation to, technology and its predictable unpredictability, is 'a social and political and not merely technical question' (Hyman, 1987: 37). Hyman cites Murray (1985), stating that: 'computer programmes that are written to control the new systems of production are geared to control labour rather than to emancipate it' (Hyman, 1987: 37). However, contemporary digitalised wellness tracking practices at work could also be rooted in the Human Relations school, where Mayo and his followers investigated wellness and fatigue as linked to early measurement techniques in the Harvard Fatigue Lab (O'Neill, 2017; Moore, 2018a). 
Preparation for the agile workplace extends beyond the types of training and visibilising of affective labour and requires specific management methods to gain insights about its value and thus to exploit it, rather than to exclusively identify how successfully workers please clients noted in customer feedback systems. Take waitressing for example, where a training manual tells servers to be:

...concerned and dependable and maybe a little provocative. I am myself, the self I most want to be. I am committed to you and I will delight you. This is how we co-produce the product of my labour: your dining experience. (Dowling, 2012: 111)

Feedback is also disseminated by virtue of affective and immaterial relations, where a customer may recommend a restaurant at no extra cost to the restaurant owner (Nunes, 2007: 189). Cognitive behavioural therapy and related psychology highlight emotional and affect regulation for stress management entitled Affect Regulation (Psychology Tools, 2016). Indeed, affect 'shadows every event', Ducey indicates, and events in care work necessitate affective labour, where the 'power to act' is reduced through widespread underappreciation of this type of work. Ducey looks at how health worker training incorporated a discourse and methods designed to aid in people's affect, or their power to act, given endemic obstacles of institutional and emotional difficulties in this work (Ducey, 2007).

The agility system is a new frontier for prescribing externalised quantification of labour and ascribing (under)value to affective labour, depleting possibilities for subjects to 
pursue what Deleuze and Guattari call becoming-minoritarian in the sense of a universal figure of consciousness, leading to real 'autonomy' (1987: 106). However, humans do not possess 'authentic' selves existing outside of capitalism along the lines Hochschild considered. Rather, the sheer possibility of there being an 'authentic' self is commodified through wellness tracking management methods. Arruzza notes that the 'the social management of affects is not an invention of capitalism', whereby, in capitalism, emotions are intentionally 'detached from us and constructed as interchangeable and measurable things that can be exchanged on the market or as skills that add to our labour power' (2014: $\mathrm{np})$. Some radical studies of the laws of value postulate that there is an 'outside' of capital that cannot be quantified (Negri transl Hardt 1999: 86). Federici argues there is no longer a conceivable 'outside' whilst we live in a capitalist hegemony (2004). Indeed, digitalised control practices surrounding agile management systems complement a range of neoliberal norms in working life which serve to subsume all aspects of everyday life to capital where workers are permanently alienated from their product, from one another and from themselves. Along these lines, new technologies are instrumental for subsumption and alienation, where monitoring technologies quantify the qualitative and reveal previously unmeasured aspects of the labour process, like mood, fatigue, psychological wellbeing, subjective self-awareness, sensitivity to privacy, stress and in the study below, further forms of affective and emotional labour.

Agility and new forms of worker tracking make workers permanently visible to management and render the sites of everyday resistance facilitated by worker-to-worker communication penetrable by management, meaning it is increasingly difficult to identify any outside to digitalised capitalism. New management methods, with influences from both 
Taylorist and Human Relations disciplines, exceed the study of physical movements seen in scientific management. Concrete labour, or work that the labourer herself explicitly enjoys the proceeds from, is subject to abstraction, and workers to alienation, in agile conditions. So, while measuring and monitoring work is not completely new, it has reached unprecedented levels in attempts to measure and commodify affect, where:

...even if the measurement of this new productive reality is impossible, because affect is not measurable, nonetheless in this very productive context, so rich in productive subjectivity, affect must be controlled. (Negri, 1999: 87)

So, quantification recognises affective and emotional labour as productive; not as an exchange worthy of consistent reward (Jarrett, 2016); but to locate profit for capital.

The following section outlines field work results from the author's study of one quantified corporate wellness initiative which the company entitled the Quantified Workplace. Project participants were, of course, not explicitly asked to self-track 'affective and emotional labour' by management in the experiment, but our findings show that via their tracking for and 'stress', 'subjective productivity', and 'wellbeing', alongside physical movement, heartrate and sleep tracking, this is what occurred. Framing affective and emotional labour as facilitative of change management at a personal level, and given the project took place in the midst of a corporate transformation both of a merger and of a management shift to an agile system, the project reveals a feature of the quantified worker trend, where a less explored terrain in worker measure becomes, potentially, an arena for management control. 


\section{The Quantified Workplace}

The Quantified Workplace project was run by one company over the period of 12 months from 2015-16 in the Netherlands, whereby the company distributed Fitbit Charge HR Activity Trackers devices to 30 employees; installed Rescuetime tracking software onto their work computers. The company provided individualised dashboards as well as a shared dashboard where all data from these tracking activities was stored and made visible to all other participants. Participants also received workday lifelog emails asking them to rate their stress, subjective productivity and wellbeing on a Likert scale from 1-5 for each item.

The project occurred during a period of change management as one multinational real estate company absorbed a smaller company of mostly work design consultants. The smaller company suggested and led the Quantified Workplace, as part of their way of indicating innovation and good practice to the larger company into which they were being merged. Funded by the British Academy/Leverhulme small grant scheme, the current author's role was to conduct independent academic research on the study via surveys and interviews. My co-investigators and I were also provided limited access to quantified and self-report data (where participants consented).

The Quantified Workplace project manager indicated that her/his intentions were to help workers adapt to an agile and mobile working environment and to see to what extent employees' self-awareness, stress, wellbeing and 'wellbilling' (which s/he described as being the amount of revenue an employee generates for the company) would be impacted during the period of transition. The company was interested in comparing subjectively and 
objectively measured productivity, as linked to health and activity tracking and 'billability' (interview with Moore 05/10/15).

Research collected over the course of the year this project ran, reveals that workers were expected to self-manage any emotional or physical impacts of the change, and selfreport via daily lifelog emails represent a year's worth of data on this process. Workers reported increased workloads and increased expectations for travel resulting from the corporate merger. While the present study did not link specific change expectations to specific forms of affective and emotional labour, there was a notable rise in areas of personalised change management expectations, as became clear through results from data gathering exercises both by the company itself and our own surveys and interviews. For example, the workday lifelog email about stress, subjective productivity and wellbeing, provided management with ways to cross-check productivity scores across individuals' perceptions and what we indicate involves affective and emotional labour, whilst also increasing workloads and responsibilities.

Interviewees readily shared their own experiences of the impact of corporate merger, noting heightened awareness of waning privacy, given the new tracking practices being rolled out; stress resulting from increased workloads and expectations for travel and mobility of work expected; feelings surrounding individual autonomy; as well as becoming more sensitised to physical and psychological wellness. Findings based on surveys and interviews showed that the highest increases in participants' expressions surrounding the rise in affective and emotional labour; from the first set of surveys and interviews at the beginning of the Quantified Workplace project, and the final surveys and interviews, 
conducted in the final weeks of the project; fell within the areas of the feelings of increased autonomy, concern for privacy, and a sense of the need for support and coaching.

The data we obtained on people's views on privacy are related to affective labour, because, for example, awareness of desire for privacy is generated from a pre-visceral sense that becomes labour when it becomes a defence mechanism against changing management practices such as corporate merger and the introduction of self-tracking at work. 'Autonomy' is typically defined as the level of control workers have over work tasks, schedules and decisions (Wheatley, 2017), which differs from the autonomist school readings, where autonomy is linked to subjectivity and emancipation. Interviewees were asked about their 'feelings of autonomy' which can be seen as a moderator of emotional and affective labour (see Johnson and Spector, 2007) because it demonstrates an arena of intimately personalised change management, where workers, despite experiencing increased workloads during the period of merger, gained feelings of independence and acted upon them. The improvement of feelings of autonomy coheres with assumptions about the capabilities of electronic devices to empower and automate specific aspects of work that were perhaps once 'ana-logged'. While the increases in autonomy could be perceived as a step toward worker resistance, sitting alongside positive feelings of autonomy, the second highest increase in the category of affective labour was participants' sensitivity to privacy. ${ }^{\text {iv }}$

Workers' responses in interviews showed some individual increases in awareness of activities that fall outside traditional work parameters which we classify as falling into the categories of affective and emotional labour. This is seen in such responses as: 
I see when I'm frustrated my heartbeat is higher.

[Participation in Quantified Workplace makes me] more conscious of activity, heartrates and wellbeing.

I learned about my feeling of productivity, so productivity has nothing to do with invoices we can send to our clients and before I was thinking, okay, productivity is like just hours I'm working for my clients, but sometimes I feel very productive, just the internal things, so therefore it helps, the way I think about productivity.

I'm more aware of the productivity, I think that's it. It's not that I directly improve my productivity, but I'm more aware of at what moments I'm productive, yeah, but that's the next step, to base some actions on that. I'm sure it makes you aware of things you do.

One participant indicated that $\mathrm{s} /$ he became more aware of her/his physical body via participation in the project:

I think awareness is even more key than total change of behaviour, but that you are more aware of your body and what's the problems for it and that you address that and start to organise your agenda around it. 
There was a high rate of exit from participation, at $75 \%$ by the end of the project. There was also a high rate of increase in people indicating they had stopped using the technologies continuously, at $73 \%$. Research results demonstrate both passive, based on interview discussions; and active resistance, based on active withdrawal. While it was not possible to interview those participants who had dropped out of the project by the time the second set of interviews were held, the survey and some interviews demonstrated difficulties in using the technology as well as high levels of uncertainty about the validity and usefulness of the project, which may have applied to others who stopped participating in the project:

A big question for me and for a few others as well, is uh, how reliable the FitBit is.

...this thing [FitBit] might be more intelligent than just recording my data.

One respondent in the second interviews indicated frustration:

I don't get any answers, I just fill in my things, but I don't get an answer if it's good or not, I just want to know if I were good and just start working.

For those who stayed with the project, responses to the question 'How/have your thoughts about the Quantified Workplace project changed?' in the second stage of interviews showed further resistance, including such statements as: 
I still have doubts about the project. And I don't wear the Fitbit very often. And when I will wear it, it is for myself and to see how active I am.

It confirmed my thoughts, which I had in the beginning. It is better to change your behaviour based on your feelings rather than a device.

After monitoring my workplace behaviour over a couple of months I found out that it didn't change a lot.

I learned not very much from it.

It became clear that the Quantified Workplace project was implemented to help employees to self-manage the impact of corporate changes and to produce data about these processes of what I have identified to be emotional and affective labour, which are areas of work that have historically been ignored by management. Data-driven technology acquired information about workers' experiences of workplace changes. Given quantification allows for seemingly 'objective reason and disinterested rationality' (Beer, 2016: 49), the very real possibility is that this kind of practice masks the intensification of performance management. New tracking technologies and their applications neutralise actions taken on the basis of big data accumulated and facilitate the new arena of human resource management called 'personal analytics'. Tracking technologies are the measure, and workers' collapse is the risk.

\section{Conclusion}


New uses of technologies in the quantified workplace are part of an emerging form of updated Taylorism, that is, processes of subordination, where quantification of new areas of work through tracking technologies may help corporations keep up with cut-throat competition. In the long term, this approach may subsume life to capital to an unsustainable degree, destroying any possibility for a qualitative outside to capitalism, which both provides the basis for capitalist relations (as use-value, labour-power, desire), and are likely to trigger continued resistance and worker struggle. At a minimum, we can speak of declining welfare for workers and the associated regime of total mobilisation and surveillance as they corrode workers' health and safety and create anxiety, burnout and overwork. Neoliberalism continues to portray such problems as workers' failures to adapt, personal psychological shortcomings or educational deficits. They are, rather, systematic effects of a particular labour process (Moore and Joyce, 2018).

Capital is tempted to invest in new technology not because it may improve the public good, regardless of the rhetoric of wellness that informs current wellbeing initiatives for workers, but rather because it can increase its profit ratios: and this article has outlined the most recent innovations in doing so. But quantification of affective and emotional labour assumes that all performers start at an equal level of competence to play such a game of survival and to thrive. Existing skills, working time capacity and/or access to social capital are ignored. These assumptions can easily result in unequal judgements and appraisals or seen as inducing extra stress and leading to work intensification and speed-up. Indeed, management did not reveal their subsequent use of data from the Quantified Workplace project to the current author (nor, it seems to the participants), but the possibilities are clear. The General Data Protection Regulation (GDPR), rolled out in May 
2018 , will deal with some of the risks that new forms of data gathering in workplaces introduce, through requiring transparency and consent as well as human intervention into any decision-making using automated and algorithmic data collection (Moore, 2017).

Power relations in capitalist reproduction reflect Marx's critiques, but machines are now more than ever before, the symbols for 'the ordering of life itself' (Merchant, 1990: 227): accelerating the labour process, dragging workers with them. Workers' responses, and explicit disengagement with the case study outlined above, demonstrate awareness to the tensions surrounding new control mechanisms; ongoing struggles in the contemporary labour process where agile is a key meme; and the urgency of reviewing of all-of-life management strategies. Workers are required to carry out further forms of affective and emotional labour to self-manage transformations and to become agile subjects under a perpetual state of alienation. The corporate project reported here demonstrates that agile systems rely on workers' affective labour to self-manage external transformation because, as the Agile Manifesto makes clear, technology inevitably transforms, meaning workers must inevitably transform, but only according to some set and quantified criteria. While the power reversal between humans and machines is assumed, agile as a system does not fully crystallise what is at stake for workers: the (im)possibility of a life outside of capitalism and beyond externalised parameters for data acquisition about working lives; encroaching alienation and subsumption as the surpluses of affective and emotional labour are perpetually abstracted; and the acceleration of the calculation of everyday lives within neoliberal capitalism, where people are increasingly told to 'measure your way out of misery' (Cain, 2017). Indeed, significant worker resistance to the Quantified Workplace project indicates that new digitalized management practices are not a fait accompli. Future 
research must focus on how alienated workers respond to such methods of measure in workplaces and identify the emerging psychosocial and even physical risks that workers face in newly quantified workplaces (Moore, 2018b).

\section{Bibliography}

The Agile Movement (2008) Agile Methodology. Available at: http://agilemethodology.org/ (accessed 09 April 2018).

Ajana, Btihaj (2017) Digital health and the biopolitics of the Quantified Self. Digital Health 3: $1-18$.

Akhtar, Pav and Moore, Phoebe (2016) The psycho-social impacts of technological change in contemporary workplaces and trade union responses. International Journal of Labour Research 8(1-2): $102-131$.

Altomonte, Guillermina (2015) Affective labour in the post-fordist transformation. Public Seminar (08/05/15). Available at: http://www.publicseminar.org/2015/05/affective-laborin-the-post-fordist-transformation/ ( accessed 09 April 2018).

Arruzza, Cinzia (2014) The capitalism of affects. Public Seminar (25/0814) Available at: http://www.publicseminar.org/2014/08/the-capitalism-of-affects/(accessed 09 April 2018). 
Automatic Data Processing (ADP) (2015) Tools and technology: Europe at a glance. Available at: http://www.adp.co.uk/adp-news/latest-press-releases/enm/33537/1/puttingwearables-to-work-new-technology-could-revolutionise-the-workplace (accessed 09 April 2018).

Beer, David (2016) Metric Power. Basingstoke: Palgrave Macmillan.

Beller, Jonathan (1998) Capital/cinema. In: Kaufman, Eleonor and Heller, Kevin Jon (eds) Deleuze and Guattari: New Mappings in Politics, Philosophy, and Culture. Minnesota: University of Minnesota Press.

Berlant, Lauren (2011) Cruel Optimism. Curham, N.C.: Duke University Press.

Blackman, Lisa (2008a) The Body: The Key Concepts. Oxford, New York: Berg.

(2008b) Affect, relationality and the problem of personality. Theory, Culture \& Society 25(1): 27-51.

------ (2010) Affect, special issue, Body \& Society 16(1).

------ (2011) Affect, performance and queer subjectivities. Cultural Studies 25(2): 183 - 199.

------ (2012) Immaterial Bodies: Affect, Embodiment, Mediation. London and New York: Sage. 
Blackman, Lisa and Featherstone, Mike (2010) Re-visioning Body \& Society. Body \& Society 16(1): $1-5$.

Bogard, William (2010) Digital resisto(e)rs. CTheory, 4-21.

Brook, Paul (2009) The alienated heart: Hochschild's emotional labour thesis and the anticapitalist politics of alienation. Capital and Class 33(2): $7-31$.

------ (2013) Emotional labour and the living personality at work: Labour power, materialist subjectivity and the dialogical self. Culture and Organization, 19(4): 332 - 352.

Cain, Ruth (2017) Measure your own misery self-quantification and the techno-recovery imperative in mental health 'mHealth' discourse. Presentation, International Initiatives in Promoting Political Economy (IIPPE), Berlin 13/09/18.

Cederström, Carl and Spicer, Andre (2015) The Wellness Syndrome. Cambridge: Polity Press.

Chartered Institute for Personnel Development (CIPD) (2014) Getting Smart About Agile Working. Available at: https://www.cipd.co.uk/knowledge/strategy/change/agile-workingreport (accessed 09 April 2018).

Cherry, M. A. (2016) People analytics and invisible labor. Saint Louis University Law Journal 61(1): $1-16$. 
Clough, Patricia T. (2008) The affective turn: Political economy, biomedia and bodies. Theory, Culture \& Society 25(1): 1-22.

Clough, Patricia T, Halley, Jean (eds.) (2007) The Affective Turn: Theorising the Social. North Carolina: Duke University Press.

Coleman, Rebecca (2012) Transforming Images: Screens Affect Futures. Routledge.

Colman, Felicity (2010) Affective self: Feminist thinking and feminist actions. Contemporary French and Francophone Studies: Sites 14(5): 543 - 552.

Crain, Marion, Poster, Winfred, and Cherry, Miriam (eds) (2016) Invisible Labour: Hidden Work in the Contemporary World. California: University of California Press.

Crawford, Kate, Lingen, Jessa, Karpii, Tero (2015) Our metrics, Ourselves: A Hundred Years of Self-Tracking from the Weight Scale to the Wrist Wearable Device. European Journal of Cultural Studies 18(4-5): 479 - 496.

Dalla Costa, Mariarosa and James, Selma (1972) The Power of Women and the Subversion of Community (England First edition). Frome and London: Butler and Tanner Ltd.

Danford, Andy, Richardson, Mike, Stewart, Paul, Tailby, Stephanie, and Upchurch, Martin (2008) Partnership high performance work systems and quality of working life. New Technology Work and Employment 23(3): 151-166. 
Deleuze, Gilles and Guattari, Felix (1987) A Thousand Plateaus: Capitalism and

Schizophrenia. Minneapolis, MN: University of Minnesota Press.

Denning, Steve (2015) How to make the whole organisation agile. Forbes 22/07/15 Available at: https://www.forbes.com/sites/stevedenning/\#60fa15e41b2d (accessed 09 April 2018).

Dewart McEwen, Karen (2017) Self-tracking Practices and digital (re)productive labour Philosophy and Technology. Epub ahead of print 09 April 2018. DOI:

https://doi.org/10.1007/s13347-017-0282-2

Dowling, Emma (2007) Producing the dining experience: measure subjectivity and the affective worker. ephemera $7(1) 117-32$.

(2012) The waitress: On affect method and (re)presentation. Cultural Studies <=> Critical Methodologies 12(2): $109-17$.

------ (2016) Valorised but not valued: Affective remuneration, social reproduction and feminist politics beyond the crisis. British Politics 11(4): $452-468$.

Dowling, Emma, Nunes, Rodrigo and Trott, Ben (2007) Immaterial and affective labour: Explored. ephemera 7 (1): 1- 7. 
Ducey, Ariel (2007) More than a job: Meaning affect and training health care workers. In:

Clough, Patricia and Halley, Jean (eds) The Affective Turn: Theorising the Social. Durham, North Carolina: Duke University Press.

Elden, Stuart (2005) Speaking Against Number: Heidegger, Language and the Politics of Calculation. Edinburgh: Edinburgh University Press.

Engster, Frank (2014) Das GEld als Maß, Mittel und Methode. Das Rechnen mit der Identität der Zeit. Berlin: Neofelis Verlag.

------ (2017) Geist, Logik, Kapital und die Technik des Maßes. Revista Opinião Filosófica, [S.I.] 7(1). ISSN 2178-1176. Available at:

http://periodico.abavaresco.com.br/index.php/opiniaofilosofica/article/view/648 (accessed 09 April 2018).

Featherstone, Mike (2010) Body image and affect in consumer culture. Body \& Society 16(1): $193-221$.

Federici, Silvia (2004) Caliban and the Witch: Women the Body and Primitive Accumulation. Autonomedia.

------ (2011) On affective labour. In: Peters, Michael A. and Bulut, Ergin (eds.) Cognitive Capitalism: Education and Digital Labour. New York: Peter Lang. 
Firth, Rhiannon (2016) Somatic pedagogies: critiquing and resisting the affective discourse of the neoliberal state from an embodied anarchist perspective. Ephemera 16(4): $121-142$.

Fleming, Peter (2015) Resisting Work: The Corporatisation of Life and is Discontents. Temple: University Press.

Fortunati, Leopoldina and Fleming, Jim (1995) The Arcane of Reproduction: Housework Prostitution Labour and Capital. Autonomedia.

Fuchs, Christian (2014) Digital labour and Karl Marx. London: Routledge.

Gandini, Alessandro (2016) The Reputation Economy Understanding Knowledge Work in Digital Society. London: Palgrave Macmillan.

Gandini, Alessandro, Pais, Ivana, Beraldo, Davide (2016) Reputation and trust on online labour markets: The reputation economy of Lance. Work Organisation, Labour and Globalisation 10(1): 27-43.

Gill, Rosalind and Pratt, Andy (2008) In the social factory? Immaterial labour, precariousness and cultural work. Theory, Culture \& Society, 25(7-8): 1-30.

Gregg, Melissa (2010) On Friday night drinks: Workplace affects in the age of the cubicle. In: Gregg, Melissa and Gregory J. Seigworth (eds) The Affect Theory Reader, Durham, NC: Duke University Press, $250-268$. 
------ (2011) Work's Intimacy. Cambridge, UK and Malden, MA: Wylie.

------ (2015) Getting things done: Productivity self-management and the order of things. Petit, Michael, Paasonen, Susanna and Hillis, Ken (eds) Networked Affect. Cambridge, MA: MIT Press, $187-202$.

Gregg, Melissa and Seigworth, Gregory J. (eds) (2010) The Affect Theory Reader. Durham, NC: Duke University Press.

Haider, Asad and Mohandesi, Salar (eds) (2015) Social Reproduction special issue. Viewpoint Magazine 5.

Hardt, Michael (1999) (trans. Negri, Antonio) Affective labour. boundary 2 26(2): 89 - 100.

Hardt, Michael and Negri, Antonio (2000) Empire. Cambridge, MA: Harvard University Press.

Hartmann, Heidi (1976) Capitalism, patriarchy, and job segregation by sex. Signs: Journal of Women in Culture and Society 1(3, Part 2): 137-169.

Hayes, L.J.B. and Moore, S. (2016) Care in a time of austerity: the electronic monitoring of homecare workers' time. Gender, Work and Organisation, Version of Record online: 20 DEC 2016 | DOI: 10.1111/gwao.12164 
Heidegger, Martin (1998) Postscript to 'What is Metaphysics?' (transl. William McNeill). Martin Heidegger: Pathmarks. New York: Cambridge University Press.

Hochschild, Arlie Russell (2012 [1983]) The Managed Heart: Commercialisation of Human Feeling. Oakland, CA: University of California Press.

Hoskyns, Catherine and Rai, Shirin (2007) Recasting the global political economy: Counting women's unpaid work. New Political Economy 12(3): 297 - 317.

Hyman, Richard (1987) Strategy or structure? Capital, labour and control. Work, Employment and Society 1(1): $25-55$.

Jarrett, Kylie (2015) Devaluing Binaries: Marxist Feminism and the Values of Consumer Labour. In Fuchs, Christian and Fisher, Eran (eds) Reconsidering Value and Labour in the Digital Age. London: Springer.

------ (2016) Feminism Labour and Digital Media: The Digital Housewife. London: Routledge.

Johnson, Hazel-Anne and Spector, Paul E. (2007) Service with a smile: Do emotional intelligence, gender, and autonomy moderate the emotional labor process? Journal of Occupational Health Psychology 12(4): 319-333.

Joroff, Michael L., Porter, William L., Feinberg, Barbara, Kukla, Chuck (2003) The agile workplace Journal of Corporate Real Estate 5(4): 293 - 311. 
Karatzogianni, Athina and Kuntsman, Adi (eds) (2012) Digital Cultures and the Politics of Emotion Feelings, Affect and Technological Change. London: Palgrave Macmillan.

Kofman, Eleonore (2012) Rethinking care through social reproduction: Articulating circuits of migration. Social Politics 19(1): $142-162$.

Kofman, Eleonore and Raghuram, Parvati (2015) Gendered Migrations and Global Social Reproduction. Palgrave.

Land, Chris and Taylor, Scott (2010) Surf's up: Work life balance and brand in a new age capitalist organization. Sociology 44(3): $395-413$

Lefebvre, Henri (1991) The Production of Space. Oxford and Cambridge, MA: WileyBlackwell.

Lupton, Deborah (2012) M-health and health promotion: The digital cyborg and surveillance society. Social Theory \& Health 10(3): 229-244.

------ (2013a) The digitally engaged patient: Self-monitoring and self-care in the digital health era. Social Theory \& Health 11(3): 256-270.

(2013b) Understanding the human machine. IEEE Technnol. Soc. Mag 32: 25-30.

------ (2013c) Quantifying the body: Monitoring and measuring health in the age of mHealth technologies. Critical Public Health 23(4): 393-403. 
(2014) Apps as artefacts: Towards a critical perspective on mobile health and medical apps. Societies 4(4): 606-622.

------ (2015) Managing and materialising data as part of self-tracking. Blog post, 22 March, https:// simplysociology.wordpress.com/2015/03/22/managing-and-materialising-data-aspart-of-self-tracking/ (accessed 09 April 2018).

(2016a) The Quantified Self: A Sociology of Self-Tracking. Cambridge, UK: Polity Press.

------ (2016b) The diverse domains of quantified selves: Self-tracking modes and dataveillance Economy and Society 45. Epub ahead of print 09 April 2018.

DOI: http://dx.doi.org/10.1080/03085147.2016.1143726

Massumi, Brian (1995) The autonomy of affect. Cultural Critique 31: 83-109.

Merchant, Carolyn (1990) The Death of Nature: Women Ecology and the Scientific Revolution. San Francisco: Bravo Ltd.

Moore, Phoebe (2017) Work and the GDPR: The future for algorithms and people analytics? $(07 / 12 / 17)$ Global Judgements and Ideas (blog post). Available at:

https://phoebevmoore.wordpress.com/2017/11/07/the-gdpr-algorithms-and-peopleanalytics/ (accessed 09 April 2018).

------- (2018a) The Quantified Self in Precarity? Work, Technology and What Counts. London: Routledge. 
------- (2018b) The threat of physical and psychosocial violence and harassment in digitalized work. Discussion paper. Work Quality Unit, International Labour Organisation: Geneva.

Moore, Phoebe and Robinson, Andrew (2016) The Quantified Self: What counts in the neoliberal workplace New Media \& Society, 18(1): 2774 - 2792.

and Piwek, Lukasz (2017) Regulating wellbeing in the brave new quantified workplace. Employee Relations 39(3): 308-316.

------- and Joyce, Simon (2018) Black box or hidden abode? Control and resistance in digitalized management. Paper presented for Lausanne University workshop digitalization and labor governance (24-25/11/17) unpublished.

Morozov, Evgeny (2013) To Save Everything, Click Here: The Folly of Technological Solutionism. New York: Public Affairs.

Nadworny, Milton J. (1955) Scientific Management and the Unions 1900-1932: A Historical Analysis. Cambridge MA: Harvard University Press.

Nafus, Dawn (2016) Quantified: Biosensing Technologies in Everyday Life. Cambridge, MA: MIT Press.

Negri, Antonio (1999) (transl. by Hardt, Michael) Value and affect. boundary 226 (2): $77-$ 88. 
Nunes, Rodrigo (2007) Forward how? Forward where? I: (Post-)Operaismo beyond the immaterial labour thesis. ephemera 7(1): $178-202$.

O'Neil, Cathy (2016) Weapons of Math Destruction: How Big Data Increases Inequality and Threatens Democracy. UK: Penguin Books.

O'Neill, Christopher (2017) Taylorism, the European science of work, and the quantified self at work. Science, Technology and Human Values 42(4): $600-621$.

Pantzar, Mika and Ruckenstein, Minna (2015) The heart of everyday analytics: Emotional, material and practical extensions in self-tracking market. Consumption Markets \& Culture 18(1): 92-109.

Pasquale, Frank (2015) The Black Box Society: The Secret Algorithms That Control Money and Information. Cambridge, MA: Harvard University Press.

Porter, Theodore M. (1996) Trust in numbers: The pursuit of objectivity in science and public life. New Jersey: Princeton University Press.

Psychology Tools (2016) Affect regulation / Emotion regulation. Available at: https://psychologytools.com/technique-affect-regulation.html (accessed 09 April 2018).

Read, Jason (2003) The Micro-Politics of Capital: Marx and the Prehistory of the Present. Albany, New York: Suny Press. 
Ruckenstein, Minna (2014) Visualized and interacted life: Personal analytics and engagements with data doubles. Societies 4(1): 68-84.

Schüll, Natasha (2016) Data for life: wearable technology and the design of self-care. Macmillan Publishers Lts. BioSocieties 11(3): 317-333.

Sedgwick, Eve Kosofsky and Frank, Adam (1995) Shame in the cybernetic fold: Reading Silvan Tomkins. Critical Inquiry, 21(2): 496-522.

Silberman, Six and Irani, Lillian (2016) Operating an employer reputation system: Lessons from Turkopticon, 2008-2015. Comparative Labour Law and Policy Journal 37(3): 505-541.

Smith, Gavin JD. (2016) Surveillance Data and Embodiment: On the work of being watched. Body \& Society 22(2): 108-139.

The Week (2015) The rise of workplace spying. Staff Analysis. Available at: http://theweekcom/articles/564263/rise-workplace-spying (accessed 09 April 2018).

Thompson, Paul and Briken, Kendra (2017) Actually existing capitalism: Some digital delusion. In: Kendra Briken, Shiona Chillas, Martin Krzywdzinski, Abigail Marks, The New Digital Workplace: How New Technologies Revolutionise Work London: Palgrave, 241 - 263. 
Thorp, Edward O. (1998) The invention of the first wearable computer. Digest of Papers. Second International Symposium on Wearable Computers (Cat. No.98EX215), Pittsburgh, PA, USA: 4-8.

Thrift, Nigel (2004) Intensities of feeling: Towards a spatial politics of affect. Geografiska Annaler: Series B, Human Geography 86(1): 57-78.

Till, Christopher (2014) Exercise as labour: Quantified self and the transformation of exercise into labour. Societies 4(3): $446-462$.

von Osten, Marion (2011) ‘Unpredictable Outcomes / Unpredictable Outcasts: On Recent Debates over Creativity and the Creative Industries', in G Raunig, G Ray and U Wuggenig (eds.), Critique of Creativity: Precarity, Subjectivity and Resistance in the "Creative Industries", London: MayFly, pp. 133-46.

Weeks, Kathi (2007) Life within and against work: Affective labor, feminist critique, and post-fordist politics. ephemera, theory \& politics in organization 7(1): 233-249.

------- Kathi (2011) The Problem with Work: Feminism Marxism Antiwork Politics and Postwork Imaginaries. Durham, NC: Duke University Press.Wetherell, Margaret (2015) Trends in the turn to affect: A social psychological critique. Body \& Society 21(2): 139-166. 
Wheatley, Daniel (2017) Autonomy in paid work and employee subjective well-being. Work and Occupations 44(3): $296-328$.

\section{BIOGRAPHICAL NOTE}

Dr Phoebe V Moore, Associate Professor in Political Economy and Technology, works at the University of Leicester in the division of Management and Organisation, School of Business.

Dr Moore has published several articles and books on labour struggle. Most recently has been writing about the impact of technologies on workers and her research has appeared in such prestigious outlets as the Financial Times, Wired, Buzzfeed, BBC Radio 4 and the Atlantic. Moore has commissioned to lead on research for the International Labour Organization of the United Nations to identify the risks we face in digitalized workplaces.

\section{POSTAL ADDRESS}

Phoebe V Moore

20 Elm Park Road, London

N3 1EB

\section{WEBSITES}

https://phoebevmoore.wordpress.com/

https://www2.le.ac.uk/departments/business/people/academic/phoebe-moore/dr-phoebev-moore 
' Reference suggestion as of April 2018: Moore, Phoebe V. (2018) Tracking affective labour for agility in the quantified workplace, Body \& Society (in press). The British Academy/Leverhulme funded the fieldwork for this paper. The project was titled 'Agility, Work and the Quantified Self' and ran 2015-2017. Co-Investigators Lukasz Piwek and lan Roper were involved with research preparation for this article.

ii Comment made while testing first wearable computer invented and designed by Claude Shannon and Edward O. Thorp at MIT to be used for casino roulette (Thorp 1998).

iii Philosophers Merleau-Ponty, Irigaray, Foucault, Deleuze and Guattari are responsible for reviving and continuing affect research which began with Spinoza's postulation on affect in Ethics Part III def 3. Clough diagrams the 'turn' to affect $(2007,2008)$, and Gregg and Seigworth (2010) note that interest was further piqued in 1995 with two pieces, Massumi's 'The Autonomy of Affect' (1995) and Sedgwick and Frank's 'Shame in the Cybernetic Fold: Reading Silvan Tomkins'. Blackman (2010) edited the special issue Affect, placing research in the field of body-studies, with possibility and without-image, emphasising collective intelligence and affective engagement where it emerges. Blackman led discussions in feminist and queer studies perspectives, touching on relations of entanglement and the prowess of intersubjectivity and relationality (2008a, 2008b, 2011, 2012). Colman identified the affective feminist self (2010) and later, Wetherell (2015) critically outlines affect research, calling for a better ontological programme, where questions of emotion, prephysiological experience and affective transmission and potentials are less bewildered. Not an exhaustive list, further research includes Clough (2008), Colman (2008, 2010), Gill and Pratt (2008), Coleman (2012), Thrift (2004), and Berlant (2011) and Haider and Mohandesi (2015) and the edited collection by Karatzogianni and Kuntsman (2012). Two recent issues in 2016 and 2017 on 'Affective Capitalism' for ephemera and 'Thinking Critically About Affect in Organizational Studies' in Organization demonstrate studies on affect continue to be cross-disciplinary. This research, however, does not address the areas of affective labour and quantification systems addressed in the present article.

iv In the first interviews, three comments indicate concern about what personal data management had access to, increasing to 21 in the final interviews. More than half of participants in a separate ADP survey expressed concern with the amount of personal data that employers can access via wearable technology (ADP, 2015). Attitudes towards privacy vary across countries, with $60 \%$ of German and a high number of British workers expressing reservations, but only $36 \%$ of Dutch employees have reservations about personal privacy at work (ADP, 2015). Based on that study, Quantified Workplace participants' concern for privacy was above average for the Netherlands, and interestingly, participation intensified sensitivity. In some cases, workers tend to feel devices 'spy' on them (The Week, 2015). 